\title{
PERdURA O EUROCENTRISMO NO ENSINO DE HISTÓRIA?
}

\author{
DOES EUROCENTRISM ENDURE IN THE TEACHING OF HISTORY?
}

\author{
(Dibele Aparecida Viana \\ Mestre em História pela Universidade Federal de Ouro Preto, aluna do doutorado em História \\ pela Universidade Federal de Ouro Preto. Ouro Preto, Minas Gerias - Brasil. \\ cibeleouro@yahoo.com.br
}

\begin{abstract}
Resumo: O ensino de História no Brasil portou, durante várias décadas, aspectos marcadamente eurocêntricos, sendo pautado, sobretudo, pelas premissas francesas da História da Civilização. A despeito dos avanços trazidos com a reformulação curricular dos anos 1980 e 1990, essa visão ainda perdurou subjacente a variadas práticas e produções do sistema de ensino e da própria percepção de mundo da sociedade brasileira. Neste artigo, problematizamos como a pauta afirmativa das representações afrodescendentes, oficialmente incorporadas ao ensino básico após a aprovação da Lei 10.639/2003, tem contribuído para o questionamento da ótica eurocêntrica nos estudos de História. De forma concomitante, defende-se o postulado de que a abordagem intercultural no ensino de História pode constituir-se como uma alternativa epistêmica, pedagógica e política ao eurocentrismo.
\end{abstract}

Palavras-chave: Ensino de história. Eurocentrismo. Livros didáticos. Lei 10.639/2003.

Abstract: The History teaching in Brazil was based on a Eurocentric paradigm since the middle of the 20th century. It was mainly based on the French premises of the History of Civilization. There was a curriculum reformulation in the 1980s and 1990s, however, despite some advances, the European vision still underlies the teaching practices, the education system researches and the own Brazilian society's world perception. In this article, we discuss how the affirmative agenda of Afro descendents representations - which was officially incorporated into the basic education after the approval of the Law 10.639 / 2003 - has contributed to the questioning of the Eurocentric perspective in History studies. At the same time, it is defended that the postulate of the intercultural approach in the History teaching can constitute itself as an epistemic, educational and political alternative to Eurocentrism.

Keywords: Teaching history. Eurocentrism. Textbooks. Law 10.639/2003.

\section{Para citar - ABNT NBR 6023:2018}

VIANA, Cibele Aparecida. Perdura o eurocentrismo no ensino de história? Cadernos de Pósgraduação, São Paulo, v. 19, n. 1, p. 73-85, jan./jun. 2020. Disponível em:

https://doi.org/10.5585/cpg.v19n1.14913. 


\section{Introdução}

A reflexão sobre a inserção de representações afrodescendentes nos livros didáticos de História implica, simultaneamente, a indagação sobre as modalidades e os níveis de incidência de uma visão eurocêntrica nessas publicações. O conceito de eurocentrismo é tomado, aqui, a partir de uma perspectiva abrangente: ele comporta não só as várias formas de expressão política, econômica e social de um imaginário legitimador da Europa como instância civilizatória no Globo, como também o enraizamento de conceitos e valores que operam na ciência e em outras formas de enxergar o mundo. (SANTOS et al.).

Formada sob tal viés eurocêntrico, a História, como disciplina, passou por diversas adaptações e transformações, visando constituir-se como uma área do saber universalista e científica. Posteriormente, essas mesmas balizas epistêmicas foram questionadas e reformuladas, principalmente no que tange aos referenciais civilizatórios, consolidados no imaginário ocidental entre meados do século XIX e a II Guerra Mundial. Afinal, a visão eurocêntrica secularmente incrustada dificulta uma interpretação mais autóctone das sociedades americanas, africanas e asiáticas, que eleja como critério de referência crítica as formulações promovidas pelos sujeitos e grupos que nelas vivem, valorizando saberes e fazeres cotidianos.

Atualmente, leituras estáticas e subordinadas das alteridades vêm sendo recusadas por perspectivas teórico-políticas como o pós-colonialismo e o decolonialismo. Os críticos vinculados a essas correntes chamam a atenção para como a ciência constituiu-se como parte integrante desse projeto de dominação, pois os discursos, ao serem enunciados ou silenciados, tanto geram pertencimentos como desqualificações.

Uma expressão da alteração da leitura eurocêntrica que vigorava no ensino de História apresenta-se, no caso brasileiro, na edição da Lei 10.639, de 9 de janeiro de 2003, a qual alterou a Lei 9.394 (de Diretrizes e Bases da Educação Nacional), de 20 de dezembro de 1996, tornando obrigatório o ensino de história e de cultura afro-brasileira, bem como da história da África e dos africanos na escola básica. Analisando essa legislação, podemos constatar que sua promulgação objetiva uma mudança em relação à compreensão da constituição histórico-cultural do Brasil, uma vez que enfatiza a atuação dos afrodescendentes no processo histórico brasileiro, nas mais variadas áreas e com toda a tensão daí decorrente. Trata-se, inclusive, de conferir legitimidade a uma demanda provinda dessa população, que reivindica reconhecimento social, igualdade jurídica e política e valorização de sua cultura.

Este artigo tem como objetivo delinear uma reconstituição das matrizes eurocêntricas nos livros didáticos de História no Brasil a partir de meados do século XIX, bem como indicar as críticas a ela proferidas a partir dos anos 1980 nos documentos oficiais, particularmente pela Lei 
10.639/2003. Postula-se, como hipótese, que a promoção de um ensino de História atento ao protagonismo afrodescendente e indígena na sociedade brasileira, veiculado inclusive em suas narrativas, simbologias e práticas, ganha maior densidade epistemológica, política e pedagógica quando tecida em abordagem intercultural. O interculturalismo suscita uma dinâmica de legitimação identitária e dialógica das culturas, das práticas e das lutas dos grupos marginalizados na sociedade brasileira, assim como o entendimento do saber histórico escolar como uma produção particularizada que intercambia, sem subordinação, as interpretações provindas da historiografia e do conhecimento científico em geral, com as visões de mundo constituídas pelos sujeitos em seu percurso intersubjetivo.

\section{$2 \mathrm{O}$ eurocentrismo nos livros didáticos de História do Brasil}

A produção dos livros didáticos de História processou-se de maneira interligada à formulação do conhecimento histórico-científico. Também este saber, durante várias décadas, delineou uma construção identitária única e homogênea, pautada no referencial das camadas letradas europeias.

Tais edições, coexistentes à constituição da História como disciplina escolar no Brasil, ${ }^{1}$ geralmente foram redigidas, por mais de um século, pela ótica de legitimação da superioridade do colonizador sobre o colonizado. Nesses textos, a população da América era apresentada como bastante distante do padrão civilizacional europeu:

\footnotetext{
[...] se atentarmos para as questões postas pelos programas, currículos, pelas produções didáticas e demais recursos e materiais de ensino [...], elas giraram, principalmente, sobre quem deveriam ser os agentes sociais privilegiados formadores da nação [...] procurou-se garantir, de maneira hegemônica, a criação de uma identidade comum, na qual os grupos étnicos formadores da nacionalidade brasileira apresentavam-se, de maneira harmônica e não conflituosa [...] portanto, o negro africano e as populações indígenas, compreendidas não em suas especificidades etnoculturais eram os cooperadores da obra colonizadora/civilizatória conduzida pelo branco português/europeu/cristão. (NADAI, 2011, p. 29).
}

Mas também emergiram alternativas, pelo menos parciais, a tais leituras. E isso ocorreu de maneira conjugada à constituição da História como disciplina escolar: um dos primeiros manuais, escrito por Bellegarde, foi editado em 1831. Embora esse livro consistisse, em grande parte, em uma tradução do livro Résumé de l'histoire du Brésil, publicado em 1828 por Ferdinand Denis, a interpretação de Bellegarde diferia do padrão civilizacional excludente então em vigor, pois ele afirmava que 
[...] ao tratar da primeira época da história do Brasil, intitulada "O Brasil antes da conquista", tema que não constava do original francês, Bellegarde critica seus compatriotas portugueses, apontando os prejuízos da ação conquistadora para os indígenas, os quais foram quase que totalmente aniquilados. $\mathrm{O}$ autor afirma que não somente as guerras têm exterminado os indígenas, "é preciso contar entre as causas da sua ruína, as moléstias 5390 importadas por nós, e a escravidão, a que eles têm por tantas vezes preferido a morte". (BELLEGARDE apud MOREIRA, s.d,p.2) .

Esse primeiro manual foi seguido pela publicação de Abreu de Lima, de 1843 (GASPARELLO, 2004, p. 77-80), que manteve a singularidade de leitura de seu antecessor. De forma geral, pode-se afirmar que

Doze anos depois de Bellegarde, Abreu e Lima ampliou a literatura histórica e didática [...]. A nação que emerge de seu compêndio não é pacífica, os heróis erram e cometem crimes e lutam por seus interesses. $O$ índio é o brasileiro que luta contra os invasores e opressores; os colonos são ambiciosos e cruéis na caça ao índio; o negro torna-se fugitivo e audaz; homens ilustres e destemidos que morrem pelo ideal republicano; patriotas que salvaram a integridade nacional com a monarquia. E, na população do século XIX, o General [Abreu e Lima] enxerga um povo com classes diferentes, escravos e libertos, que participam de movimentos de rua. (GASPARELLO, 2015, p. 49).

Porém, o manual didático de história do Brasil que se consagrou como discurso pedagógico “oficial da nação" foi Lições de História do Brasil, cuja primeira edição data de 1861, mas que obteve publicações sucessivas por todo o período Imperial e Primeira República. Esse compêndio didatizava o pensamento de Varnhagen e do IHGB, apresentando os grupos africanos, afrodescendentes e indígenas como inferiores ao branco civilizado. Assim, os povos autóctones

\footnotetext{
[...] são mencionados em seu compêndio no momento da descrição do território descoberto. São tratados sempre como "gentios". [...] Macedo apresenta um olhar etnológico superficial em relação aos indígenas apontando as curiosidades do seu cotidiano e as diferenças em relação ao homem civilizado. Outra observação deve-se ao fato do autor referir-se aos indígenas como elemento passado. [...] Os "gentios do Brasil" eram considerados como um povo na sua infância, rudes e selvagens, alheios à civilização. O tom se ameniza quando chega a temática da família indígena. Mas quando se trata das relações sociais, a falta de um governo centralizador e de religião, os caracteriza como desprovidos de elementos essenciais de civilização. [...] (MOREIRA, s. d., p. 5393).
}

Uma nova fase da história dos livros didáticos no ensino secundário inicia-se com a publicação, em 1900, de História do Brasil, de autoria de João Ribeiro. Produzida no período republicano, quando questões identitárias da nacionalidade exigiam uma nova configuração, a obra foi dividida em duas edições distintas, uma destinada ao curso primário e outra ao ginasial. João Ribeiro deslocou a ênfase da história político-administrativa para uma história sociocultural, sob inspiração das ciências sociais em constituição na Alemanha. Assim, segundo ele, a fisionomia do país derivaria "do colono, do jesuíta e do mameluco, da acção dos índios e dos escravos negros. Esses foram os que descobriram as minas, instituíram a criação do gado e a agricultura, catechicasam longinquas tribus". (RIBEIRO apud MOREIRA, s. d., p. 5.394). 
Não obstante, “assim como em Macedo, o índio é apresentado nos manuais de Ribeiro como 'uma gente dá mais ínfima civilização'. Em ambas as obras [...] é corrente a interpretação do índio acivilizado, tendo como parâmetro o comportamento europeu”. (RIBEIRO apud MOREIRA, s. d., p. 5.394). Entretanto, percebe-se em Ribeiro a visão do índio como formador do povo "mameluco", do povo brasileiro. Em suma, segundo Alfredo Bosi, para João Ribeiro, "o índio, o negro e o mestiço, mulato ou caboclo são vistos como seres dignos de simpatia, embora mais toscos, mais rudes, mais instintivos, em suma, mais primitivos, e, palavra que escapa, inferior ao branco". (BOSI, 1992, p.332).

Em sequência, são editados novos livros didáticos, como os de Pedro Couto, em 1918 (GASPARELLO, 2004, p. 183-185), ou Quadros da História Pátria, publicado em 1918, de autoria de Max Fleius e Basílio de Magalhães. ((GASPARELLO, 2004, p. 190). Também nesses produtos didáticos,

Podemos concluir que os indígenas são apresentados [...] pelo que eles diferenciam do modelo de civilização europeia. A expressão "sem Fé, sem Lei e sem Rei” dá o tom da narração sobre os indígenas nos livros didáticos de história do Brasil. De modo geral, os textos didáticos apresentaram o indígena como um sujeito racializado com base nas definições de origem e classificação; religião, relações sociais e familiares, habitação, usos e costumes, primeiros contatos, influências, características físicas e línguas. [...]. (MOREIRA, s.d., p. 5.398).

Os livros didáticos de história do Brasil do primeiro período republicano vêm sendo também analisados em função de seus registros gráficos. Nesse sentido, a dissertação de mestrado de Carla Sacramento indica que o livro de Rocha Pombo, Nossa Pátria: narração dos factos da História do Brasil, atravéz da sua evolução com muitas gravuras explicativas, de 1925, possuía 27 imagens, num total de 147, que ilustravam agentes sociais africanos ou afrodescendentes:

[...] foi possível perceber que, na maior parte das vezes, em 14 delas $(51,85 \%)$ os negros foram associados ao trabalho nas minas, fazendas e serviços domésticos e, em segundo lugar, aparecem em situações em que estavam conversando com seus pares, seja numa vila, seja numa fazenda, em situação festiva. Apenas em uma imagem visual foi mostrado um castigo físico decorrente da necessidade de o autor demonstrar aos leitores o que significava o pelourinho e qual era a sua função. (SACRAMENTO, 2013, p. 82).

Ora, quando tais manuais apresentam a imagem de um afrodescendente de forma indissociável do trabalho manual e dos castigos corporais, eles reforçam tal posição social e simbólica.

Na década de 1930, sobretudo após o advento do Estado Novo, assiste-se à publicação da reforma educacional Francisco Campos, cuja ênfase dirige-se à renovação metodológica, proveniente, em parte, da expansão das ideias da Escola Nova (MAGALHÃES, 2003, p. 169). Outra mudança empreendida adveio da Lei Orgânica do Ensino Secundário, também conhecida como Reforma Gustavo Capanema, que conferiu ao professor autonomia didática e restabeleceu 
a História do Brasil como disciplina autônoma. Especificamente no âmbito étnico-racial promovido pelo ensino de história, tornou-se vitoriosa a tese da "democracia racial".

"A teoria da democracia racial, é preciso salientar, foi criada para fundamentar uma homogeneização cultural e omitir as diferenças e desigualdades sociais. Serviu para fortalecer a ideia de uma História Nacional caracterizada pela ausência de conflitos [...]" (BITTENCOURT apud KARNAL, 2005, p. 199). Sob essa ótica, o negro era representado como pacífico diante do trabalho escravo e o índio era tido como "bom selvagem", ambos, por sua vez, trariam contribuições "exóticas" ou "típicas" da identidade nacional.

Durante as décadas de 1950 e 1960 foram estabelecidas novas expectativas em relação ao ensino de história: nesse contexto de pós-guerra, a história foi entendida a partir da sucessão linear dos centros econômicos hegemônicos de cana-de-açúcar, mineração, café e industrialização. No tocante às abordagens de cunho étnico-racial, as pesquisas indicam que

[...] a escrita escolar de História do Brasil, produzida entre 1950 e 1995, operou pelo menos com duas referências centrais para aludir e localizar uma espécie de recorte histórico, relativo aos povos africanos que para o Brasil vieram no contexto do tráfico transatlântico: a África como lugar geográfico e de produção de escravos. [...] (CONCEIÇÃO, 2017.p.38).

Com o advento da ditadura civil-militar, em 1964, perdurou uma concepção de História calcada no encadeamento sucessivo de datas, acontecimentos e personagens históricos. No que concerne ao estudo das relações étnico-raciais, a pesquisadora Adriana Gomes Tavares indica a manutenção das concepções hegemônicas dos períodos anteriores:

\begin{abstract}
Esta afirmação evidencia-se ao analisarmos o livro de Leonilda Montandon, Vamos conhecer nossa história? $\mathrm{Na}$ sua $5^{\mathrm{a}}$ edição, de 1962. [...] A autora deixa transparecer claramente que a mestiçagem que envolve o sangue africano não é pura. O preconceito neste trecho é nítido. [...] A descoberta das minas e os serviços da lavoura exigiam trabalhadores e os pretos ofereciam a necessária resistência para tais trabalhos. Por esta razão, começou o tráfico de negros os quais eram caçados e presos nas selvas africanas como se fossem animais. [...]. É interessante pontuar que o livro de Leonilda Montandon é destinado às crianças da $4^{\text {a }}$ série do ensino primário. (TAVARES, s.d., p. 74).
\end{abstract}

Novas propostas metodológicas e programas para o ensino de História na Educação Básica só se desenvolveram com mais propriedade no final dos anos 1970, momento em que o regime ditatorial começou a ser mais fortemente contestado e as instituições políticas repressoras foram enfraquecidas. Os embates e entraves do governo para elaboração de diretrizes de ensino possibilitaram que professores, sobretudo das redes públicas municipais e estaduais, elaborassem seus próprios currículos, os quais, entretanto, foram várias vezes copiados de propostas curriculares já existentes (FARIAS JUNIOR, 2013). 
Sobretudo no período pós-ditadura militar, passou a ser conferida grande relevância às práticas de memória dos afrodescendentes e indígenas. Pode-se mesmo afirmar que a noção de "dever de memória" passou a ser apropriada por esses grupos em dois sentidos. De um lado, como estratégia de luta política no campo simbólico, com o objetivo de construção de ações memorialistas que gerassem entendimentos acerca da responsabilidade do Estado e/ou de grupos elitizados e instituições sociais, em torno dos atos opressivos empreendidos contra grupos particulares em contextos específicos. De outro, buscando produzir repercussões de natureza reparatórias em campos diversos (político, histórico, jurídico, financeiro, educacional e midiático).

\section{$3 \mathrm{O}$ eurocentrismo questionado na produção didática de História na contemporaneidade}

A perspectiva inclusiva de reconhecimento étnico-racial não proveio, portanto, unicamente da iniciativa dos segmentos intelectualizados. Muito pelo contrário. Ela foi resultante, sobretudo, das pressões políticas oriundas dos movimentos negros, aos quais somou-se a mobilização indígena. Podemos citar como exemplo dessas lutas a criação, nas décadas de 1930 e 1940, da Frente Negra Brasileira, do Teatro Experimental do Negro (TEN) e da Associação Cultural do Negro (ACN) (CASTRO; ARAUJO; CEBULSKI; MARÇAL, 2008).

As lutas políticas pela igualdade étnico-racial intensificaram-se ainda mais no contexto de redemocratização política do país. Uma das conquistas obtidas foi o estabelecimento, na Constituição de 1988, do compromisso de proteção "às manifestações das culturas populares, indígenas e afro-brasileiras, e das de outros grupos participantes do processo civilizatório nacional". (BRASIL, 1988. Art. 215). Na passagem do século XX para o XXI, a busca pelo reconhecimento dos direitos de viés étnico-racial assumiu outras tantas facetas, uma vez que as manifestações implícitas de racismo continuavam a perdurar na sociedade brasileira, conforme indicado por todos os índices relativos aos níveis de empobrecimento, escolaridade, emprego, mortandade. Assim, podem ser citadas como exemplos emblemáticos dessas reivindicações a Marcha Zumbi dos Palmares, contra o Racismo, pela Cidadania e pela Vida (1995) e a III Conferência Mundial contra Racismo, Discriminação Racial, Xenofobia e Intolerância Correlata (2001).

No campo educacional, tais pressões foram inicialmente canalizadas nos debates em torno dos Parâmetros Curriculares Nacionais (PCNs), que abordaram a temática do pluralismo nas práticas de ensino. Os Parâmetros Curriculares Nacionais (PCNs), publicados em 1998, consistem em um conjunto de nove volumes que buscam estabelecer uma proposta curricular para a Escola Fundamental em dimensões nacionais, ancorada na flexibilização curricular e em uma concepção de escola voltada para a construção da cidadania, sem, contudo, constituir-se como um currículo obrigatório. Nesse sentido, os PCNs articulam a necessidade da incorporação de elementos das 
diversidades regionais, culturais, políticas etc. presentes na sociedade brasileira e próximos aos alunos e professores, com referências de amplitude nacional, supostamente comuns a todas as regiões do país. Com isso, pretende-se criar nas escolas condições que permitam aos jovens ter acesso ao conjunto de conhecimentos socialmente elaborados e reconhecidos como necessários ao exercício da cidadania. (ROZA, 2014).

Quanto à temática "História afro-brasileira", os PCNs indicam uma mudança de enfoque quando trata da existência da pluralidade do patrimônio sociocultural brasileiro, destacando que o tratamento homogêneo dado à composição étnico-racial pela produção didática contribuía para a subjugação e aniquilamento desse patrimônio na sociedade brasileira. (BRASIL, 1998).

Os PCNs, documento que antecedeu as Diretrizes Curriculares Nacionais da Educação Básica, foram o "embrião" para a formulação das Diretrizes que possui um tom mais claramente político que o dos PCNs, já que trata diretamente da questão do combate ao racismo. Debatendo conceitos de raça, identidade negra, racismo, democracia racial, cultura negra, cultura afro-brasileira e indígena, pluralidade cultural e cultura brasileira, a política educacional proposta pelas Diretrizes exige o aprofundamento desses conceitos e sua contextualização no processo histórico. Para além do evidente envolvimento de educadores, as Diretrizes evidenciam aos profissionais de História o desafio de aprofundar a reflexão sobre a história da formação étnico racial da população brasileira, em suas dimensões de pesquisa e ensino. Esse documento também chama atenção para a necessidade de medidas que proporcionem aos cidadãos reivindicar o empoderamento de seu pertencimento étnico-racial - sejam eles de descendência africana, indígena etc. - para, assim, implementarem conjuntamente ações que resultem na construção de uma nação efetivamente democrática, em que todos tenham igualmente seus direitos garantidos e sua identidade valorizada. (BRASIL, 2013).

O fato de esses documentos serem elaborados por governos de orientação política diferenciada mostra que essa intervenção nas propostas educacionais foi resultante da organização dos movimentos negros na sociedade brasileira e de seu reconhecimento como força política crescente depois do processo de redemocratização do país. Os documentos demonstram que não é mais possível pensar o Brasil sem uma discussão social.

As Diretrizes trazem como meta para a escola o combate ao racismo, ao propor que esta instituição insira no âmbito das disciplinas escolares a discussão das relações raciais no país, tantas vezes silenciada ou desqualificada pelas avaliações de que o Brasil é uma democracia racial.

A despeito desses avanços, o documento das Diretrizes ainda trata a diversidade cultural de forma dicotômica, como afirma Hebe Mattos e Martha Abreu. Com isso, dificulta-se a possibilidade 
de abordagem da cultura como um processo que está em constante mudança pelo intercâmbio entre os diversos povos:

Em termos culturais, a tendência do documento das "Diretrizes" é afirmar a existência de uma cultura negra e africana em oposição a um padrão cultural e estético branco e europeu. Persistiria no Brasil um "imaginário étnico-racial” que ignora ou pouco valoriza as raízes indígena, africana e asiática de nossa cultura (Brasil, 2004:14). As "Diretrizes", com essa perspectiva, acabam sugerindo e defendendo a existência das culturas europeia, africana e indígena, abrindo mão de pensar o quanto as identidades culturais são construções e campos de luta também historicamente datados, como a própria utilização dos termos que fazem referência ao conceito de raça. Os processos de troca cultural e hibridização das culturas não são mencionados como possibilidades reais de trabalho com culturas (MATTOS; ABREU, 2008, p. 9).

Nos governos Fernando Henrique e Lula, foram sancionadas várias leis ${ }^{2}$ resultantes das reivindicações do movimento negro e que se referiam aos direitos de reparação dessa população (COSTA, 2013). No campo educacional, o presidente Lula sancionou em 2003 a Lei 10.639, que modifica a Lei de Diretrizes e Bases da Educação de 1996, determinando o estudo da História da África e dos Africanos de forma interdisciplinar, com especial ênfase às disciplinas de História e Artes.

No ano seguinte à promulgação da Lei 10.639, foram também editadas as Diretriz̧es Curriculares Nacionais para Educação das Relações Étnico-Raciais, as quais encontram-se justamente vinculadas à questão do reconhecimento das pluralidades e direitos identitários:

Reconhecimento implica justiça e iguais direitos sociais, civis, culturais e econômicos, bem como valorização da diversidade daquilo que distingue os negros dos outros grupos que compõem a população brasileira. E isto requer mudança nos discursos, raciocínios, lógicas, gestos, posturas, modo de tratar as pessoas negras. Requer também Diretrizes Curriculares Nacionais para a Educação das Relações Étnico-Raciais e para o Ensino de História e Cultura Afro-Brasileira e Africana que se conheça a sua história e cultura apresentadas, explicadas, buscando-se especificamente desconstruir o mito da democracia racial na sociedade brasileira. (BRASIL, 2004, p. 11-12).

Essas legislações constituíram-se em uma conquista para o reconhecimento social dos grupos negros. Elas abarcam uma série de importantes questões, pois não se resumem a discutir a questão da escravidão e do preconceito, problematizando também a importância do reconhecimento político cultural dos afrodescendentes, entendidos como sujeitos históricos, com reivindicações, embates e conquistas.

A aprovação da Lei de 2003 trouxe para a esfera institucional da escola uma série de questões que antes eram geralmente silenciadas ou pelo menos tratadas superficialmente pela comunidade escolar. Pensar o espaço escolar como um local de diferentes sujeitos, como território atravessado pela diversidade cultural, é pensar o trabalho que o professor exercerá enquanto mediador das relações de ensino-aprendizagem, relações éticas e conflitos de ideologias. Dessa forma, propiciar um ensino em que a nação brasileira emerja como fundamentalmente pluriétnica 
e que nenhum grupo ou povo seja superior ao outro é importante para construir, junto ao alunado, a noção de heterogeneidade cultural, diferença e respeito.

Sob tal perspectiva e dialogando com a reflexão de Pollak (1989) acerca das imbricações políticas vinculadas aos processos de valorização de determinadas memórias sociais e ao silenciamento de outras, podemos compreender que a edição da Lei 10.639/03 apresenta-se como a oportunidade de tornar visíveis grupos historicamente espoliados, denunciar tais violências e explorações e contribuir para a constituição e intensificação de uma história e de um ensino de História inclusivo.

\section{Conclusão}

A superação do eurocentrismo também significa trazer as vozes dos sujeitos que foram silenciadas ou deturpadas para dentro do campo de interpretação da experiência social. Nesse aspecto, é central a perspectiva intercultural, ao invés da multicultural. Isso implica reconhecer que a herança histórica não pode ser simplesmente obliterada ou substituída por novos códigos político-culturais, por mais válidos que eles sejam em termos éticos:

\footnotetext{
Nesse sentido, essa posição [intercultural] situa-se em confronto com todas as visões diferencialistas que favorecem processos radicais de afirmação de identidades culturais específicas, assim como com as perspectivas assimilacionistas que não valorizam a explicitação da riqueza das diferenças culturais. (CANDAU, 2008, p. 51).
}

Assim, um ensino de História intercultural, e não eurocêntrico, não deixa de reconhecer a presença de um imaginário de transfundo europeu em nossa sociedade brasileira, com todos os limites, contradições e realizações desse imaginário. A proposta do interculturalismo é que não se assuma mais esse imaginário europeu ou ocidental (branco, científico, masculino etc.) como referencial, e sim como um elemento a ser apropriado em função das práticas cotidianas e refeito por elas.

Em paralelo, é possível tecer aproximações entre a proposta intercultural e o pensamento decolonial, que também defende a produção simultaneamente científica e política, uma produção de conhecimento com base em discursos e saberes antes invisibilizados. Podemos considerar a abordagem decolonial como parte de um projeto que tem desconstruído criticamente uma determinada configuração de ordem social: ocidental, branca, masculina, monogâmica, cristã etc. Nesse âmbito, a perspectiva decolonial possibilita uma ampliação de paradigmas ao tornar possíveis diálogos menos hierárquicos nos projetos educativos, nas formas de pensarmos as políticas públicas e no modo de representarmos os estratos da sociedade que são relegados à invisibilidade.

Por isso, estamos de acordo que a "união" da interculturalidade e da decolonialidade promove a diversidade, como nos coloca Catherine Wash: 


\begin{abstract}
De maneira ainda mais ampla, proponho a interculturalidade crítica como ferramenta pedagógica que questiona continuamente a racialização, subalternização, inferiorização e seus padrões de poder, visibiliza maneiras diferentes de ser, viver e saber e busca o desenvolvimento e criação de compreensões e condições que não só articulam e fazem dialogar as diferenças num marco de legitimidade, dignidade, igualdade, equidade e respeito, mas que - ao mesmo tempo - alentam a criação de modos "outros" - de pensar, ser, estar, aprender, ensinar, sonhar e viver que cruzam fronteiras. A interculturalidade crítica e a decolonialidade, nesse sentido, são projetos, processos e lutas que se entrecruzam conceitualmente e pedagogicamente, alentando forças, iniciativas e perspectivas éticas que fazem questionar, transformar, sacudir, rearticular e construir. (WALSH apud CANDAU, 2009. p. 25).
\end{abstract}

\title{
Referências
}

BITTENCOURT, Circe. Identidade nacional e Ensino de História do Brasil. In: KARNAL, Leandro (org.). História na Sala de Aula: Conceitos, práticas e propostas. 3. ed. São Paulo: Contexto, 2005.

BOSI, Alfredo. A. Dialética da Colonižação. São Paulo: Companhia das Letras, 1992. Disponível em: http://www.ufrgs.br/cdrom/bosi/. Acesso em: 2 ago. 2019.

BRASIL. Constituição Federal. 1988.

BRASIL. Diretrizes Curriculares Nacionais da Educação Básica. 2013. Disponível em: http://portal.mec.gov.br/index.php?option $=$ com_docman\&view $=$ download\&alias $=15548$-d-cn-educacao-basica-nova-pdf\&Itemid=30192. Acesso em: 2 abr. 2019.

BRASIL. Diretrizes Curriculares Nacionais para a Educação das Relações Étnico-Raciais e para o Ensino de História e Cultura Afro-Brasileira e Africana. 2004. Disponível em:

http://www.acaoeducativa.org.br/fdh/wp-content/uploads/2012/10/DCN-s-Educacao-dasRelacoes-Etnico-Raciais.pdf. Acesso em: 4 abr. 2019.

BRASIL. Lei 10.6399 jan. 2003. Disponível em: http://www.planalto.gov.br/ccivil_03/leis/2003/L10.639.htm. Acesso em: 2 abr. 2019.

CANDAU, Vera Maria. Direitos humanos, educação e interculturalidade: as tensões entre igualdade e diferença. In: Revista Brasileira de Educação, v. 13 n. 37 jan./abr. 2008.

CANDAU, Vera Maria (org.). Educação Intercultural na América Latina: entre concepções, tensões e propostas. Rio de janeiro: 7 letras, 2009.

CASTRO, Cristiana Gonzaga Candido de Souza; ARAUJO, Débora Cristina; CEBULSKI, Márcia Cristina; MARÇAL, Maria Antônia. O ensino de bistória e cultura afro-brasileira e africana no Paraná: legislação, políticas afirmativas e formação docente. Disponível em:

http://www.pucpr.br/eventos/educere/educere2008/anais/pdf/1001_958.pdf. Acesso em: 2 abr. 2019.

CONCEIÇÃO, Maria Telvira. Os Discursos da Racialização da África nos Livros Didáticos Brasileiros de História (1950 a 1995). In: Educação \& Realidade, Porto Alegre, v. 42, n. 1, p. 35-58, jan./mar. 2017.

COSTA, Warley. A escrita escolar da História da África e dos afro-brasileiros: entre leis e resoluções. In: PEREIRA, Amílcar Araújo; MONTEIRO, Ana Maria (org.). Ensino de Historia e Culturas e Indígenas. Pallas: 2013. 
FARIAS JUNIOR, José Petrúcio de. Ensino de História: trajetórias de uma disciplina na educação básica. In: Acta Scientiarum. Human and Social Sciences . Maringá, v. 35, n. 1, p. 127-134, jan.-jun. 2013.

GASPARELLO, Arlete Medeiros. A nação imaginada nos livros didáticos do século XIX. In: Cadernos de História da Educação, v. 14, n. 1, jan./abr. 2015.

GASPARELLO, Arlete Medeiros. Construtores de Identidade: a pedagogia da nação nos livros didáticos da escola secundária brasileira. São Paulo: Iglu, 2004.

MAGALHÃES, Marcelo de Souza. História e cidadania: por que ensinar história hoje? In: ABREU, Martha; SOIHET, Rachel (org.). Ensino de História: conceitos, temáticas e metodologia. Rio de Janeiro: Casa da Palavra, 2003.

MATTOS, Hebe; ABREU. Em torno das "Diretrizes Curriculares Nacionais para a Educação das Relações Étnico-raciais e para o Ensino de História e Cultura Afro-brasileira e Africanas" Uma conversa com historiadores. In: Estudos Históricos. Rio de Janeiro, n. 4, 2008.

MOREIRA, Kênia. Índios nos livros didáticos de bistória do Brasil na Primeira República (1889-1930). Disponível em: http://www.pph.uem.br/cih/anais/trabalhos/216.pdf. Acesso em: 11 abr. 2019.

NADAI, Elza. O ensino de História e a "pedagogia do cidadão". In: PINSKY, J. (org.). In: O ensino de História e a criação do fato. São Paulo: Contexto, 2011.

POLLAK, Michael. Memória, Esquecimento, Silêncio. In: Estudos Históricos, Rio de Janeiro, vol. 2, n. 3, p. 3-15, 1989.

SANTOS, Pedro; NICODEMO, T.; PEREIRA Mateus. Historiografias periféricas em perspectiva global ou transnacional: o eurocentrismo em questão. In: Estudos históricos, v. 30, p.161-186, 2017

ROZA, Luciano Magela. A bistória afro-brasileira pós-abolição em livros didáticos. 2014. Tese (Programa de Pós-Graduação em Educação) - Faculdade de Educação, Universidade Federal de Minas Gerais, Belo Horizonte, 2014.

SACRAMENTO, Cristina Carla. De "Gente da África" a "Nossos irmãos": quem são os negros nos livros didáticos de História do Brasil de Rocha Pombo e Viriato Corrêa? 2013. Dissertação (Mestrado em Educação) - Universidade Federal de São João del-Rei, São João del-Rei, 2013.

TAVARES, Adriana Gomes. A representação do negro nos livros didáticos de História em Minas Gerais (1960-2005). Disponível em:

http://www.fae.ufmg.br/portalmineiro/conteudo/externos/4cpehemg/Textos/pdf/5a_1.pdf. Acesso em: 12 abr. 2019.

TOLEDO, Maria Aparecida Leopoldino Tursi. A disciplina de História no Império brasileiro. Revista HISTEDBR On-line. Campinas, n. 17, p. 1-10, mar. 2005. Disponível em: http://www.histedbr.fe.unicamp.br/revista/revis/revis17/art01_17.pdf. Acesso em: 16 abr. 2019. 
Notas

${ }^{1} \mathrm{O}$ marco temporal para o estabelecimento desta disciplina foi o ano de 1838, quando o saber histórico torna-se um componente curricular do Imperial Colégio Pedro II (TOLEDO, 2005).

2 O Decreto 3.551, de 2000, que institui o patrimônio cultural e imaterial a partir da valorização da cultura afrobrasileira; o Decreto 4.228, de 2002, que institui o Programa Nacional de Ações Afirmativas; o Decreto 4.887, de 2003, que regulariza o direito à terra dos descendentes de escravos. 